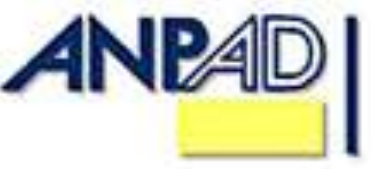

Available online at http://www.anpad.org.br/bar

BAR, Rio de Janeiro, v. 11, n. 4, art. 4 pp. 441-454, Oct./Dec. 2014

http://dx.doi.org/10.1590/1807-7692bar2014130002

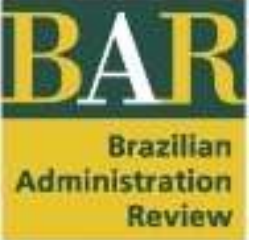

$(\mathrm{cc}) \mathbf{E}$

\title{
Understanding Supply Networks from Complex Adaptive Systems
}

Jamur Johnas Marchi

E-mail address: jamur.marchi@unipampa.edu.br Universidade Federal de Santa Catarina - PPGAdm/UFSC

UFSC, Campus Universitário Trindade, 88040-900, Florianópolis, SC, Brazil.

Rolf Hermann Erdmann

E-mail address: erdmann@cse.ufsc.br

Universidade Federal de Santa Catarina - PPGAdm/UFSC UFSC, Campus Universitário Trindade, 88040-900, Florianópolis, SC, Brazil.

Carlos Manuel Taboada Rodriguez

E-mail address: taboada@deps.ufsc.br

Universidade Federal de Santa Catarina - PPGEP/UFSC

UFSC, Campus Universitário Trindade, 88040-900, Florianópolis, SC, Brazil.

Received 19 July 2013; received in revised form $3^{\text {rd }}$ July 2014 (this paper has been with the authors for two revisions); accepted 15 July 2014; published online $1^{\text {st }}$ October 2014. 


\begin{abstract}
This theoretical paper is based on complex adaptive systems (CAS) that integrate dynamic and holistic elements, aiming to discuss supply networks as complex systems and their dynamic and co-evolutionary processes. The CAS approach can give clues to understand the dynamic nature and co-evolution of supply networks because it consists of an approach that incorporates systems and complexity. This paper's overall contribution is to reinforce the theoretical discussion of studies that have addressed supply chain issues, such as CAS.
\end{abstract}

Key words: supply networks; complex adaptive systems; supply chains. 


\section{Introduction}

In recent decades, businesses searching for competitive advantages became fragmented through reengineering (Davenport, 1994) and outsourcing (Porter, 1989). On the other hand, companies stopped working in isolation, resulting in distinct organizational configurations, such as alliances, groups, networks and other forms of organization becoming significant strategic alternatives (Gulati, Nohria, \& Zaheer, 2000; Lorange \& Roos, 1996).

The supply network (Lamming, Johnsen, Zheng, \& Harland, 2000) is one such configuration, and is primarily studied regarding aspects related to the integration and management of all the companies involved (Power, 2005). Research shows the difficulties in overcoming static and deterministic approaches supply network levels (Harland, 1996; Mills, Schmitz, \& Frizelle, 2004). The need for studying dynamic aspects of business networks continues (Dagnino, Levanti, Mocciaro, \& Destri, 2008). Other studies indicate that traditional approaches to managing supply chains are difficult to adapt to uncertain and turbulent environments, and suggest that the complex systems approach contributes to new understandings for management of supply networks (Christopher \& Holweg, 2011; Dong, 2014).

An analytical framework based in a holistic and complex perspective may contribute towards this purpose (Dagnino et al., 2008; Power, 2005). Complex Adaptive Systems (CAS) is an approach that gathers aspects to understand the dichotomy between control and emergency in a supply network (Choi, Dooley, \& Rungtusanathamal, 2001). Therefore, this theoretical essay aims to discuss supply networks as complex adaptive systems. In order to achieve this goal, the methodological design consisted of a deep reflection on these two approaches. This design is suitable when the aim of the research is to deepen or broaden the discussion (Meneghetti, 2011) about a particular topic. In this way, the concepts between the two approaches are approximated.

\section{Supply Networks}

In the beginning, in operation management fields, logistics was the discipline that had the responsibility of offering solutions for companies' integration (Christopher, 2009). However, researchers and practitioners perceived that the new established dynamic required other solutions beyond the ones that had already been offered by the logistic. Therefore, logistics would focus on supply flow (Cooper, Lambert, \& Pagh, 1997; Lambert, Cooper, \& Pagh, 1998), but require the addition of supply chain management.

Supply chain management can be defined as the "management of upstream and downstream relationships with suppliers and customers to deliver more value to the customer, at a lower cost to the supply chain as a whole" (Christopher, 2009, p. 4). Supplies, information, finances and knowledge are involved in such relationships. The term supply network refers to a set of supply chains (Harland, 1996; Lamming et al., 2000). In this article, we use the term network in order to understand that a company works with a network of suppliers and suppliers' suppliers, forming a system of connected autonomous organizations.

\section{Different levels of supply networks analysis}

The dynamic aspects of supply networks are linked to more strategic levels of analysis (Harland, 1996; Mills et al., 2004). Harland (1996) proposed four levels of analysis to study supply chains. The first level refers to the supply and information flow in a company, that is, the internal focus. The second level involves relationships with immediate suppliers, which is called the dyad-level. The third level of analysis involves suppliers' suppliers, as well as customers and customers' customers, comprising chain 
links. Finally, the fourth level is concerned with the network management of interconnected companies and involves providing products and services demanded by final customers.

From a company's point of view, four perspectives are recommended for supply chain management (Mills et al., 2004). The first perspective is the upstream: as a purchaser dealing with suppliers. The second one is the downstream: as a supplier dealing with customers. The third perspective is the static network: as an auditor of positions within its supply network, with a static and comparative view. The fourth perspective is the dynamic network, in which a company is a strategist seeking opportunities to improve its position within the network or to create new networks, using a strategic, dynamic and long-term view.

Harland's network perspective has advantages as it allows the selection of partnerships in the network, and it establishes a competitive position in a network, allowing comparisons among competitors (Harland, 1996). Mills, Schmitz and Frizelle (2004) third perspective (the static perspective) corroborates this. Notably, this view is concerned with network structure; i.e., the bonds that tie companies to their competitive positions, either internal or external.

The network dynamic perspective is concerned with perceiving how a supply network develops, and which dynamic is involved in an evolutionary process (Mills et al., 2004). It also dedicates itself to comprehend how new supply networks can be shaped, and which choice mechanisms are relevant to this process. For instance, they show how supply networks are developed through decision making, such as deciding between making and buying.

Nevertheless, Mills et al. (2004) approach, even though concerned with the dynamic features of a supply network over time, fails to point out behaviors and effects produced by the choices between purchasing and producing. Mainly, how such behaviors and effects can modify a network structure for new adaptations or creations of new networks, when responding to new market situations. Mills et al. (2004) suggest that theory complexity helps to elucidate supply network behavior.

In this sense, our argument is close to the IMP Group study. They adopt an approach of relationship networks to study business relations. They developed the ARA model, which is based on actors, resources and activity on a network (Häkansson \& Snehota, 1995). In the ARA model, network actors are perceived according to the activities they perform and resources they possess and consume. Actors are linked to each other through these resources and activities. The activities can be very different, for example, production, marketing or transportation. The resources could be technological, productive or even knowledge.

Despite being relatively old, the ARA model has, in itself, elements that are still quite current. For instance, according to Häkansson and Snehota (1995), in a supplier-company the relationships are recurring structural aspects, such as continuity, complexity, symmetry and informality, and also, procedural aspects, such as adaptations, cooperation and conflict, social interaction and routinization. However, ARA is a strongly situational model, which can only be useful for analysis of a supply network if it is presented in a static manner. For example, what activities are linked, what resources are being combined, used or developed in the network, and which links the actors have to facilitate or constrain partnerships.

The CAS view might contribute to and amplify the dynamic capability of the ARA model by including behaviors and effects into present-future relationships in supply networks, increasing the space for predictability and possibilities. In the CAS view, the supply network evolves and self-organizes when companies make choices related to survival over time (Pathak, Day, Nair, Sawaya, \& Kristal, 2007). The CAS view can see an intertwined relationship between cooperation and competition, in which disputes, agreements and alliances change the process from static to dynamic, adaptive and coevolutionary. 


\section{Complex Adaptive Systems}

One of the complex theories is complex adaptive systems. Complex systems consist of systems with multiple interactions among their parts or agents (Holland, 1992). This abstraction allows visualizing that the human brain, an individual, a group, an organization, society, the global community and even the environment might be understood to be complex adaptive systems (Stacey, 1996).

A number of problems can be confronted through CAS, among them, encouraging economic innovation, anticipating changes in global trade, understanding markets and preserving ecosystems (Holland, 2006). For instance, McCarthy (2003) used CAS to elaborate a technology management model, and Rammel, Stagl and Wilfingal (2007) utilized the CAS to build an agenda for natural resource management. In organizational studies, some essential elements of CAS models that can help shape organizational systems are highlighted as agents with schemas, self-organizing networks supported by energy imports, co-evolution at the edge of chaos, systemic evolution and recombination (Anderson, 1999).

\section{Elements, behaviors and effects}

It is possible to revise and complement the elements, behaviors and effects based on Wycisk, McKelvey and Hülsmann's review (2008). These three dimensions form a framework (Figure 1) that can help to understand the dynamic co-evolution of supply networks.

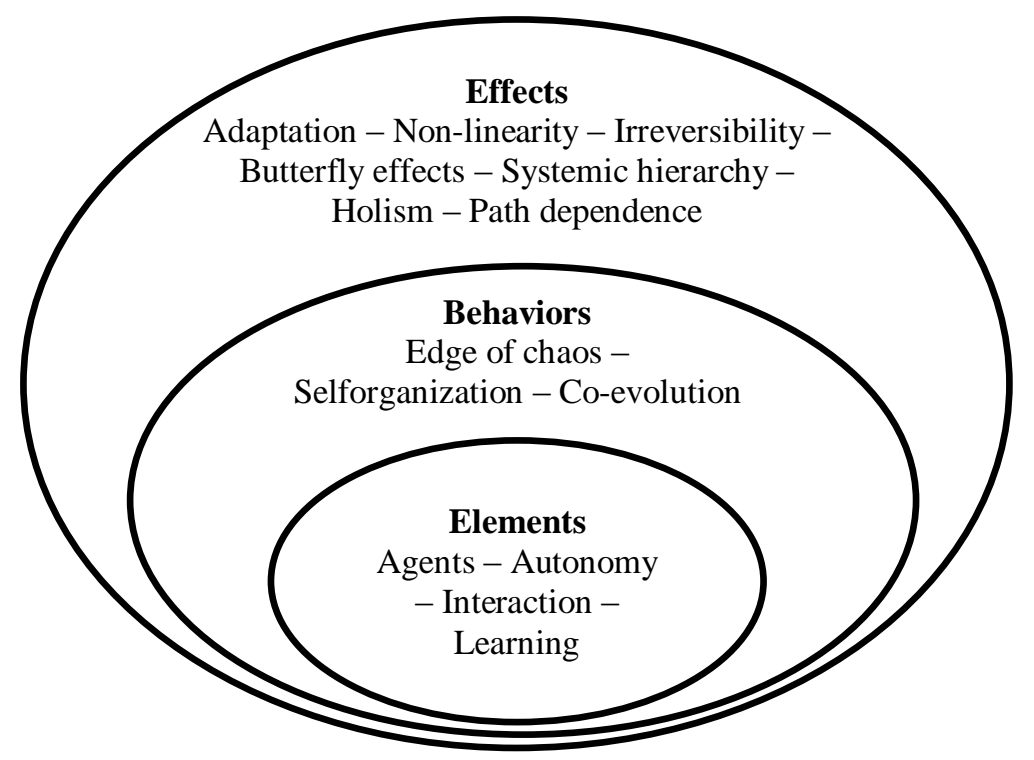

Figure 1. Elements, Behaviors and Effects of CAS.

Source: Based and expanded from Wycisk, C., McKelvey, B., \& Hülsmann, M. (2008). "Smart parts" supply networks as complex adaptive systems: analysis and implications. International Journal of Physical Distribution \& Logistics Management, 38(2), 108-125. doi: 10.1108/09600030810861198

A CAS tends to operate with the following logic: the agents, with relative autonomy, act through schemes or lax rule modules. In addition, the individuals search for better rewards by recombining interactions between agents (Anderson, 1999; Holland, 2006). In a CAS, the set of rules and agents evolves over time and improves to interact with the system better (Holland, 2006), which means learning occurs. The space created by the system dynamic is set between order and chaos (Brown \& Eisenhardt, 1998; Kauffman, 1993). The system, which is self-organized at the edge of chaos, could be the ideal locus for the creative processes of learning and innovation (Stacey, 1995, 1996). Thus, the system may co-evolve together with its agents. 
The CAS behavior provokes, in the system, effects, characteristics and different orders as emergent novelties. Nevertheless, what emerges as a result is not always going to be positive. Behaviors and characteristics can be contrary to the system, meaning that the whole may be smaller than the sum of its parts (Morin, 1990; Stacey, 1995). The emergent result refers to the combined and synergistic effects of parts; however, it does not refer to the sum of individual results. It occurs that individual performance could give power or mitigate other performance. The effects or emergent results that a CAS can present are adaptation, nonlinearity, butterfly effect, systemic hierarchy, holism and path dependence.

\section{Supply Networks from the CAS Perspective}

The elements that compose a CAS are agents, autonomous actions, interaction and learning. It is possible to find these elements inside a supply network. The agents are firms or groups of companies that work together through partnerships or alliances in which they share rules and economic benefits (Choi et al., 2001). Firms can be suppliers, manufacturers, retailers, customers; each with its function in the system. Such firms create an environment of intense interaction motivated by exchanges of material, financial and informational resources, and also knowledge. Such exchanges are produced by the pursuit of each company's goals individual (Häkansson \& Snehota, 1995; Wycisk, McKelvey, \& Hülsmann, 2008).

Companies are entities that have relative autonomy to operate in sectors and markets. In a supply network, the companies and their sub-unities have autonomous levels through delegation and decentralization in order to plan and decide (Wycisk et al., 2008). Nevertheless, autonomy is not complete because companies are surrounded by contractual and legal obligations, as well as the forces that exist in the sectors in which they operate; for example, the asymmetric power that exists in a supplier-buyer relationship.

In the context of inter-business interactions, the learning capacity of supply networks can allow the "exchange of worth knowledge and existing capacities and/or co-produce new knowledge and capabilities" (Dagnino et al., 2008, p. 81). Learning is a less-explored element in supply networks, but one that might bring more durable and competitive advantages for companies. Table 1 presents the summary of CAS elements in supply networks.

Table 1

\section{Elements of Supply Networks}

\begin{tabular}{ll}
\hline $\begin{array}{l}\text { CAS Elements } \\
\text { (Holland, 2006) }\end{array}$ & Elements of supply networks \\
\hline Agents & $\begin{array}{l}\text { Actors (Häkansson \& Snehota, 1995). } \\
\text { Suppliers, manufacturers, retailers, customers (Wycisk } \text { et al., 2008). } \\
\text { Building groups of companies that work together through partnerships or alliances } \\
\text { (Choi } \text { et al., 2001). }\end{array}$ \\
Resources and Activities (Häkansson \& Snehota, 1995). \\
Interaction & $\begin{array}{l}\text { Exchanges of material resources, finance, information and knowledge (Wycisk et } \\
\text { al., 2008). }\end{array}$ \\
& $\begin{array}{l}\text { Companies are entities that have relative autonomy to operate in sectors and markets } \\
\text { (Wycisk } \text { et al., 2008). }\end{array}$ \\
Autonomy & Exchange of knowledge and new knowledge and capabilities (Dagnino et al., 2008). \\
\hline
\end{tabular}


In supply networks, it is possible to perceive CAS behaviors with self-organization, edge of chaos and co-evolution. Some networks are controlled by powerful companies, Toyota for instance. However, in most supply networks, there is no control organ (Wycisk et al., 2008) in charge of coordinating activities and exercising governance. Such activities self-organize from interactions, and they are motivated by the interests of each company. In a supply network, self-organization occurs because some firms agree with the parameters set by others. "Inter-firm relationships and institutional mechanisms through which the non-market coordination of chain activities is achieved" also exist (Humphrey \& Schmitz, 2001, p. 4).

For Wycisk et al. (2008), if self-organized processes occurred in a logistics system there would be a limit between order and chaos, in the edge of chaos. The supply network behavior operates within this dynamic between order and chaos. Networks are forms of organization between markets and hierarchy (Powell, 1990). By analogy, chaos is the coordination via market, while order is the full internalization of assets. These opposite extremes are unattractive to agents while, in the space between them (order/chaos), supply network agents may reduce transaction costs and have opportunities to learn from each other, and co-evolve together.

In the management field, the edge of chaos is also called creative space (Stacey, 1995), in fact, it has to do with the level of rigidity and control. If a supply network is rather rigid in rules, parameters, forms of thinking and acting or, on the contrary, it is too flexible, it will limit creative space either through stagnation or collapse. The creative space is the locus for innovative initiatives in process, products and services.

Co-evolution occurs as a behavior arises in supply networks, when they are situated in the edge of chaos. In this space, the companies, networks and environment are modified recursively, in constant evolution. For instance, "when an acquiring company develops a supplier of parts as a supplier system, that the action, in turn, creates a new set of second-tier suppliers that is going to deliver parts to that supplier new system" (Choi et al., 2001, p. 356). Co-evolutionary behavior is the result of agents interacting and learning, over time; for example, buyers helping suppliers in order to implement quality standards directly or by introducing a service provider. Table 2 presents the summary of behaviors in supply networks.

Table 2

\section{Behaviors of the Supply Networks}

\begin{tabular}{|c|c|}
\hline CAS Behaviors & Behaviors of the supply networks \\
\hline Self-organization & There is no control organ (Wycisk et al., 2008). \\
\hline (Holland, 2006) & It can exist different levels of control versus autonomy (Choi et al., 2001). \\
\hline \multirow{3}{*}{$\begin{array}{l}\text { Edge of the chaos } \\
\text { (Prigogine \& Stengers, 1997) }\end{array}$} & $\begin{array}{l}\text { Networks are forms of organization between market and hierarchy (Powell, } \\
\text { 1990). }\end{array}$ \\
\hline & Creative space (Stacey, 1995). \\
\hline & Rigidity and control (Wycisk et al., 2008). \\
\hline $\begin{array}{l}\text { Co-evolution } \\
\text { (Kaufman, 1993) }\end{array}$ & $\begin{array}{l}\text { "Developing a supplier can create a new suppliers' system" (Choi et al., } \\
\text { 2001, p. 356). }\end{array}$ \\
\hline
\end{tabular}

About the effects, the supply network by itself corresponds to an emergent result because the structure of a network depends on the companies' corresponding choices (Choi et al., 2001). A possible objective for supply networks is to know how to match choices in order to achieve efficient emergent behaviors (Wycisk et al., 2008). Then, by understanding how the effects emerge in the supply network, choices can be coordinated in an efficient way. In this essay, the studied emergent effects were adaptation, nonlinearity, butterfly effect, holism, systemic hierarchy and path dependence. 
The adaptation constitutes of the dynamic process of system changes, over a period, with the goal of conforming to itself and with the environment. This time could be long or relatively short, depending on the stimulus. There are two underlying problems: recognizing which rules and actions are working well in order to maintain them, and finding out which rules and actions are generating problems, in order to eliminate them. This is because adaptation is the result of an intricate set of interactions, within a given time and space (Holland, 1995).

For a long time, supply networks tended to adapt themselves to their environment, i.e., shape their structures, add or exclude relationships between agents (for instance, connecting with new suppliers and serving as new customers). Also, they tended to change their physical capacities (for instance, the implementation of new technologies) and the adaptation of behavioral processes, that is, strategy changes (Wycisk et al., 2008). This way, the supply network interacts with environmental demands and modifies the environment for its competitors (Choi et al., 2001), for itself and its members.

In this context of adaptation, nonlinear effects may occur. Facing continuous adaptations, a CAS may present nonlinear effects, which are unpredictable. Thus, the results are irreversible, too. In other words, they cannot be erased after they are already made and they cannot return to the initial state of their parts ${ }^{(1)}$ (Prigogine \& Stengers, 1997).

In a supply network, cost reduction efforts made by a large buyer can lead to random results (Choi et al., 2001). If the supply chain possesses nonlinearity it will not be possible to control its operations, essentially, by deterministic methods. Deterministic refers to the notion that the final management goal of supply networks is to completely control a network (Choi et al., 2001). Nevertheless, a management goal could be able to mix agents' control and autonomy in order to improve (Choi et al., 2001). Combining these items, the chance a network has to reach a creative space between order and chaos increases.

The butterfly effect consists as an example of nonlinear effects. CAS may exhibit butterfly effect results that consists of extreme events provoked by small actions (Lorenz, 1963). This effect can originate from numerous interactions of positive or negative feedbacks by agents and nonlinear behaviors, among other small events that are included in CAS (Wycisk et al., 2008), making it difficult to forecast.

In supply networks, this is called bullwhip effect. Some companies' actions affect other companies along the supply chain because there is interdependency between them. The bullwhip effect describes how small initial changes (for instance, in customers' demands) can result in chaotic and extreme events along the network, by a nonlinear process (Wycisk et al., 2008). In other words, Choi, Dooley and Rungtusanathamal (2001) suggest that a small change in the downstream supply chain can cause amplified effects in upstream supply chain phases. According to Lee, Padmanabhan and Whangal (1997), there are four major causes of the bullwhip effect in supply chains. They are: update the demand forecast; bulk purchases, encouraged by discounts; price fluctuations, for example, due to promotions; and the scarcity game, when the supply chain offers less than the demand and vendors begin to ration their downstream products.

Systemic hierarchy consists of the creation of multiple levels that operate by following similar rules. According to Simon (1962), the capability of a system adaptation will broaden if the subsystems are quasi-decomposable. Different levels of aggregation could emerge in the system from autonomous agents, and such aggregated levels, even though they are temporarily stable, are adaptive and can be recombined to allow more adaptability to the superior levels (Holland, 1992).

Observed vertically, a supply network is, by definition, multi-level: supplier, manufacturer, distributor, retailer and customer (Wycisk et al., 2008). These subsystems may be stable or unstable depending on the kind of contract in which they are linked (long-term or short-term). Also, informal agreements might exist, such as some unique partnerships. For instance, for a particular purpose, such as developing a new material or product, small aggregates of firms can self-organize. Thus, the structure is undone as soon as the activities are concluded. 
Holism is related to the holographic principle, which not only means that the part is printed in the whole, but also, that the whole is printed in the parts, too (Morin, 1990). Holism, in a supply network, is related to the rules of the game. For example, according to Humphrey and Schmitz (2001) the key rules that guide companies in global supply chains are: what should be produced, how it should be produced, when it should be produced, how much should be produced and pricing. Another example, according to Surana, Kumara, Greaves and Raghavan (2005), is that the holism evidence, in a supply network, might be perceived when there are the same concerns on each level of the system. For instance, lower-priced products, storage, improved quality and faster delivery. In other words, there is a shared and similar logical printing, which guides the actions at various levels towards a common end. For a firm in a supply network, this logic is often named as creating customer value. These rules are followed by all agents in the network, under penalty of being excluded from the game. The rules apply to an agent and, at the same time, to the entire supply network.

The process of interaction and adaptation, over time, develops an overlapping set of decisions that make up history and path dependence. The notion of path dependence originates from Arthur's (1999) ideas about the notion of increasing returns. His ideas explain that systems, in an economy, might have more than one equilibrium point, and such points can be approached through positive feedbacks; therefore, one point leads to another and so forth. "The past history affects the future development and there might be several paths or standards that a system can follow" (Mitleton-Kelly, 2003, p. 17).

Knowing that the choices of the past actions can be irreversible, in a supply network, the trajectory of actions may influence and determine future paths. For instance, the Toyota network trajectory in search for quality clearly shows that system improvements are evolutions from past decisions. However, it does not mean that there are no choices for the future; to the contrary, there are some possibilities. Nevertheless, these possibilities are located in a place whose range is largely determined by the trajectory that companies and supply chains are already taking.

Table 3

\section{Effects of the Supply Networks}

\begin{tabular}{|c|c|}
\hline Emergent effects of the CAS & Emergent effects of the supply networks \\
\hline $\begin{array}{l}\text { Adaptation } \\
\text { (Holland, 1995) }\end{array}$ & $\begin{array}{l}\text { Shaping their structures, adding or excluding the relationships } \\
\text { between agents, changing their physical capacities and adaptation of } \\
\text { behavioral processes, namely, strategic changes (Wycisk et al., } \\
\text { 2008). }\end{array}$ \\
\hline $\begin{array}{l}\text { Non-linearity } \\
\text { (Prigogine \& Stengers, 1997; Thiétart } \\
\text { \& Forgues, 1995) }\end{array}$ & $\begin{array}{l}\text { An effort of cost reductions by a large buyer can lead to random } \\
\text { results (Choi et al., 2001). }\end{array}$ \\
\hline $\begin{array}{l}\text { Butterfly effect } \\
\text { (Lorenz, 1963) }\end{array}$ & $\begin{array}{l}\text { The bullwhip effect (Lee, Padmanabhan, \& Whangal, 1997; Wycisk } \\
\text { et al., 2008). }\end{array}$ \\
\hline $\begin{array}{l}\text { Systemic hierarchy } \\
\text { (Simon, 1962) }\end{array}$ & $\begin{array}{l}\text { Observing a supply network vertically, it is by definition a multi- } \\
\text { level one: supplier, manufacturer, distributor, retailer and customer } \\
\text { (Wycisk et al., 2008). }\end{array}$ \\
\hline \multirow[t]{2}{*}{$\begin{array}{l}\text { Holism } \\
\text { (Morin, 1990) }\end{array}$} & $\begin{array}{l}\text { What should be produced, how it should be produced, when it should } \\
\text { be produced, how much should be produced and pricing (Humphrey } \\
\& \text { Schmitz, 2001). }\end{array}$ \\
\hline & $\begin{array}{l}\text { Lower-priced products and storage, improved quality and faster } \\
\text { deliveries (Surana, Kumara, Greaves, \& Raghavan, 2005). }\end{array}$ \\
\hline $\begin{array}{l}\text { Path dependence } \\
\text { (Arthur, 1999; Mitleton-Kelly, 2003) }\end{array}$ & The path can determine future choices and possibilities. \\
\hline
\end{tabular}


In this section, it was possible to observe that the elements, behaviors and effects of CAS can be observed in supply chains. It reinforced the argument that supply chains can be understood as complex systems. One understands supply networks as complex adaptive supply networks, in other words, a system of connected autonomous organizations that make choices and co-evolve together, on dependent trajectories.

\section{Implications for the supply networks management}

The aim of this paper was to propose an analytical framework to improve the understanding of supply networks as complex systems, and their co-evolutionary and dynamic processes. In this way, it is possible to point out implications for the management of supply networks with the aim to reinforce the argument, in a way that might help create flexible supply networks. Thereby, one can begin to think about working with complexity and not against it. For example, in a supply network involved in a turbulent environment, control efforts can lead to rigidity of structures and interactions (Christopher \& Holweg, 2011), and working against complexity. This rigidity may limit agents' flexibility and learning. On the other hand, if we have strategies that anticipate uncertainties, we can dampen turbulence and disruptions, by operating with complexity.

\section{Stimulating mechanisms that promote interactions}

This means that, in managing supply chains, the link (upstream and downstream) between agents are sources of potential value as partnerships and alliances. The applicability of the ARA model (Häkansson \& Snehota, 1995) is particularly relevant for this intention. For example, buyer-supplier relations can move beyond contractual supply relationships, and include elements for the development of new materials (raw material or component). Interactions have to be considered not only in material or financial terms, but also in terms of information and knowledge exchange. Another example is relationships with competitors. A company should be prepared to share assets (distribution centers, transportation and factory), even with competitors (Christopher \& Holweg, 2011), in a competitive relationship. On the other hand, if a network does not stimulate interactions, it will tend to weaken and get close to market relationships, which in CAS language means avoiding the edge of the chaos zone.

\section{Encouraging autonomy in a network}

Autonomy is a natural property of a system, and it needs to be understood and encouraged. For example, instead of locking in a supplier, exclusively, companies can consider alternative sourcing for key materials and components (Christopher \& Holweg, 2011). This allows suppliers to meet other businesses and form other networks. Such stimulus for autonomy is relevant to the flexibility of a supply network, and also, to amplify the exchange of information and knowledge.

\section{Understanding that learning depends on interaction and autonomy levels}

The previous implications (promoting interaction and autonomy) were about conditions for flexibility and learning in the supply networks. Learning is relevant because it improves the responsiveness to changes in context, creating innovative answers and competitive advantage. In others words, learning is the dynamic of knowledge exchange. According to Lavie (2006), learning and its consequent outcome are achieved through intentionally shared assets, and also by inbound and outbound spillovers obtained through interactions between companies. For example, agents' interaction helping to develop new knowledge about products, services and materials that could not be achieved if pursued in isolation. 


\section{Recognizing creative space}

In the supply network, if firms encourage autonomy and interactions they will facilitate developing of learning. The resultant behaviors are self-organizing and co-evolving in a creative space. Therefore, between the rigidity/control and autonomy/flexibility in which a system self-organizes, learns and creates novelty, there exists a space where firms in the network co-evolve with supply networks and the environment in a dynamic and nonlinear manner. Management for co-evolution seems to be a current demand for supply networks. For instance, an upstream view and the improvements in production systems by adopting lean tools such as kanban are being used with parts suppliers for fast replacement. In product development, one specific supplier can participate early on in the project. From a downstream view, marketing actions may create demands for products still in development. Also, in order to recognize changes in the environment and suggest changes to projects, new market opportunities and technology might be perceived and included in future agendas.

\section{Developing capabilities to influence positive emergent effects}

Since nothing is perfect, the effects that may emerge in supply chains tend to escape companies' control. Furthermore, effects could worsen the situation instead of helping, i.e., they can be negative. Therefore, the network management role is to identify and develop capabilities that encourage positive effects and, in the same way, restrict negative effects. It is possible to mention three examples: first, the structure flexibility of a supply network can be based on holism and systemic hierarchy. Simple rules can be disseminated, shared, learned and efficiently replaced throughout supply network levels. Project teams can be created with representatives from upstream and downstream companies in order to address common problems or answer any other demand. These capabilities help the continuous adaptation of the supply network.

Second, changing is a constant in supply networks. Thereby, practitioners need to change the way of perceiving reality by leaving an atomistic and static view, and adopting a systemic and dynamic view. In others words, they have to recognize that making isolated decisions may produce negative effects for supply networks as a whole. Thus, if each company tries to maximize its profits exclusively, it will lead a network to inferior results (the bullwhip effect, for instance).

Third, recognizing that path dependence is necessary. The view in which only the future is important is partial. The set of possibilities for decisions taken in the present, in part, is defined by the dependent trajectory of networks and their members. For instance, in organizational theory, "the outcome of path-dependent capability development is more likely to be positive for the firm with asset complementarities, learning specialization or increasing returns to scale and scope prevent imitation by the competitors" (Vergne \& Durand, 2010, p. 740). In supply networks, this evidence could be reinforced through agents' interactions.

It is important to highlight, before concluding the argument of this essay, the limitations of applying CAS theory to supply networks. It is possible to highlight three limitations: first, CAS theory originates from the study of living systems, however, supply networks are social-technical systems with human and nonhuman elements. Second, the human element, to the contrary of other elements in living systems, can hide his/her intentions, motivations, and interests. CAS hardly catches such abilities for it can only identify the agents and their interactions; however, it is not able to reach the level of intentions, nor the reasons for the actions and interactions among specific agents. Third, the concepts discussed here require empirical studies to strengthen the theoretical propositions and test hypotheses. 


\section{Conclusion}

This theoretical essay aimed to achieve a theoretical approximation with the theory of complex adaptive systems in order to visualize contributions for a better appreciation of the evolutionary and dynamic processes of supply networks.

An important find in the literature, is the evidence that the CAS approach, which incorporates system and complexity, may give clues to perceive the dynamic nature and co-evolution of supply networks. Therefore, supply networks can be seen as quasi-living complex adaptive systems (Wycisk et $a l .$, 2008). The analyses of wider levels as systems may help because the evolutionary dynamic nature of supply networks can be similar to CAS.

In summary, it is possible to highlight that practitioners need to perceive the complex logic of supply network management. For instance, seeking the best for one agent will not necessarily lead to better results for the entire network. In their turn, researchers need to develop studies, especially empirical ones, related to the complex aspects of the supply chains, such as studies related to the bullwhip effect.

\section{Note} ${ }^{1}$ For a more detailed comprehension, we suggest reading Thiétart and Forgues (1995), which presents a perspective of
organizations as nonlinear dynamic systems.

\section{References}

Anderson, P. (1999). Complexity theory and organization science. Organization Science, 10(3), 216232. doi: $10.1287 /$ orsc. 10.3 .216

Arthur, W. B. (1999). Complexity and the economy. Science, 284(5411), 107-109. doi: $10.1126 /$ science.284.5411.107

Brown, S. L., \& Eisenhardt, K. M. (1998). Competing on the edge. Boston: Harvard Business School Press.

Choi, T. Y., Dooley, K. J., \& Rungtusanatham, M. (2001). Supply networks and complex adaptive systems: control versus emergence. Journal of Operations Management, 19(3), 351-366. doi: $10.1016 / \mathrm{S} 0272-6963(00) 00068-1$

Christopher, M. (2009). Logística e gerenciamento da cadeia de suprimentos: criando redes que agregam valor (2a ed.). São Paulo, SP: Cengage Learning.

Christopher, M., \& Holweg, M. (2011). "Supply chain 2.0": managing supply chains in the era of turbulence. International Journal of Physical Distribution \& Logistics Management, 41(1), 6382. doi: 10.1108/09600031111101439

Cooper, M. C., Lambert, D. M., \& Pagh, J. D. (1997). Supply chain management: more than a new name for logistics. The International Journal of Logistics Management, 8(1), 1-14. doi: 10.1108/09574099710805556 
Dagnino, G. B., Levanti, G., \& Destri, A. M. L. (2008). Evolutionary dynamics of inter-firm networks: a complex systems perspective. Advances in Strategic Management, 25(8), 67-129. doi: $10.1016 / \mathrm{S} 0742-3322(08) 25003-5$

Davenport, T. H. (1994). Reengenharia de processos: como inovar na empresa através da tecnologia da informação (5a ed.). Rio de Janeiro, RJ: Editora Campus.

Dong, M. A. (2014). Research on supply chain models and its dynamical character based on complex system view. Journal of Applied Sciences, 14(9), 932-937. doi: 10.3923/jas.2014.932.937

Gulati, R., Nohria, N., \& Zaheer, A. (2000). Strategic networks. Strategic Management Journal, 21(3), 203-215. doi: 10.1002/(SICI)1097-0266(200003)21:3<203::AID-SMJ102>3.0.CO;2-K

Häkansson, H., \& Snehota, I. (1995). Developing relationships in business networks. London: Routledge. Retrieved from http://www.impgroup.org/uploads/books/0-415-11570-1.pdf

Harland, C. M. (1996). Supply chain management: relationships, chains and networks. British Journal of Management, 7(s1), S63-S80. doi: 10.1111/j.1467-8551.1996.tb00148.x

Holland, J. H. (1992). Complex adaptive systems. Daedalus, 121(1), 17-30. Retrieved from http://www.jstor.org/stable/20025416

Holland, J. H. (1995). Hidden order: how adaptation builds complexity. Cambridge: Perseus Books.

Holland, J. H. (2006). Studying complex adaptive systems. Journal of Systems Science and Complexity, 19(1), 1-8. doi: 10.1007/s11424-006-0001-z

Humphrey, J., \& Schmitz, H. (2001). Governance in global value chains. IDS Bulletin, 32(3), 19-29. doi: 10.1111/j.1759-5436.2001.mp32003003.x

Kauffman, S. (1993). At home in the universe. New York: Oxford University Press.

Lambert, D. M., Cooper, M. C., \& Pagh, J. D. (1998). Supply chain management: implementation issues and research opportunities. The International Journal of Logistics Management, 9(2), 1-20. doi: $10.1108 / 09574099810805807$

Lamming, R., Johnsen, T., Zheng, J., \& Harland, C. (2000). An initial classification of supply networks. International Journal of Operations \& Production Management, 20(6), 675-691. doi: $10.1108 / 01443570010321667$

Lavie, D. (2006). The competitive advantage of interconnected firms: an extension of the resource-based view. Academy of Management Review, 31(3), 638-658. doi: 10.1177/014920630102700610

Lee, H. L., Padmanabhan, V., \& Whang, S. (1997). The bullwhip effect in supply chains. Sloan Management Review, 38(3), 93-102.

Lorange, P., \& Roos, J. (1996). Alianças estratégicas: formação, implementação e evolução. São Paulo: Editora Atlas.

Lorenz, E. N. (1963). Deterministic nonperiodic flow. Journal of the Atmospheric Sciences, 20(2), 130141. doi: 10.1175/1520-0469(1963)020<0130:DNF>2.0.CO;2

McCarthy, I. P. (2003). Technology management: a complex adaptive systems approach. International Journal Technology Management, 25(8), 728-745.

Meneghetti, F. K. (2011). O que é um ensaio teórico? Revista de Administração Contemporânea, 15(2), 320-332. Retrieved from http://www.scielo.br/pdf/rac/v15n2/v15n2a10.pdf. doi: 10.1590/S141565552011000200010 
Mills, J., Schmitz, J., \& Frizelle, G. (2004). A strategic review of supply networks. International Journal of Operations \& Production Management, 24(10), 1012-1036. doi: 10.1108/01443570410558058

Mitleton-Kelly, E. (Ed.). (2003). Complex systems and evolutionary perspectives on organizations: the application of complexity theory to organizations. Oxford, UK: Elsevier Science Ltd.

Morin, E. (1990). Introdução ao pensamento complexo (4a ed.). Lisboa: ESF.

Pathak, S. D., Day, J. M., Nair, A., Sawaya, W. J., \& Kristal, M. M. (2007). Complexity and adaptivity in supply networks: building supply network theory using a complex adaptive systems perspective. Decision Sciences, 38(4), 547-580. doi: 10.1111/j.1540-5915.2007.00170.x

Porter, M. E. (1989). Vantagem competitiva (11a ed.). Rio de Janeiro, RJ: Editora Campus.

Powell, W. W. (1990). Neither market nor hierarchy: network forms of organization. Research in Organizational Behavior, 12, 295-336.

Power, D. (2005). Supply chain management integration and implementation: a literature review. Supply Chain Management: An International Journal, 10(4), 252-263. doi: $10.1108 / 13598540510612721$

Prigogine, I., \& Stengers, I. (1997). A nova aliança: metamorfose da ciência (3a ed.). Brasília, DF: Universidade de Brasília.

Rammel, C., Stagl, S., \& Wilfing, H. (2007). Managing complex adaptive systems: a co-evolutionary perspective on natural resource management. Ecological Economics, 63(1), 9-21. doi: 10.1016/j.ecolecon.2006.12.014

Simon, H. A. (1962). The architecture of complexity. Proceedings of the American Philosophical Society, 106(6), 467-482. Retrieved from http://links.jstor.org/sici?sici=0003049X\%2819621212\%29106\%3A6\%3C467\%3ATAOC\%3E2.0.CO\%3B2-1

Stacey, R. D. (1995). The science of complexity: an alternative perspective for strategic change processes. Strategic Management Journal, 16(6), 477-495. doi: 10.1002/smj.4250160606

Stacey, R. D. (1996). Complexity and creativity in organizations. San Francisco: Berrett-Koehler Publishers.

Surana, A., Kumara, S., Greaves, M., \& Raghavan, U. N. (2005). Supply-chain networks: a complex adaptive systems perspective. International Journal of Production Research, 43(20), 4235-4265. doi: 10.1080/00207540500142274

Thiétart, R. A., \& Forgues, B. (1995). Chaos theory and organization. Organization Science, 6(1), 1931. doi: $10.1287 /$ orsc.6.1.19

Vergne, J., \& Durand, R. (2010). The missing link between the theory and empirics of path dependence: conceptual clarification, testability issue, and methodological implications. Journal of Management Studies, 47(4), 737-759. doi: 10.1111/j.1467-6486.2010.00913.x

Wycisk, C., McKelvey, B., \& Hülsmann, M. (2008). "Smart parts” supply networks as complex adaptive systems: analysis and implications. International Journal of Physical Distribution \& Logistics Management, 38(2), 108-125. doi: 10.1108/09600030810861198 